\title{
Impact of resilience on the improvement of depressive symptoms after cognitive therapies for depression in a sample of young adults
}

\author{
Impacto da resiliência na melhora dos sintomas depressivos após terapias \\ cognitivas para depressão em uma amostra de adultos jovens
}

\author{
Caroline Elizabeth Konradt, ${ }^{1}$ Taiane de Azevedo Cardoso, ${ }^{1,2}$ Thaíse Campos Mondin, ${ }^{1}$ Luciano Dias de Mattos Souza, ${ }^{1}$ \\ Flavio Kapczinski, ${ }^{2,3}$ Ricardo Azevedo da Silva, ${ }^{1}$ Karen Jansen $^{1}$
}

\begin{abstract}
Introduction: Few studies have evaluated positive measures for therapeutic response. Thus, the objective of this study was to assess the effects of resilience on severity of depressive and anxious symptoms after brief cognitive psychotherapy for depression.

Methods: This was a clinical follow-up study nested in a randomized clinical trial of cognitive therapies. The Resilience Scale was applied at baseline. The Hamilton Anxiety Rating Scale (HARS) and the Hamilton Depression Rating Scale (HDRS) were used at baseline, post-intervention, and at sixmonth follow-up.

Results: Sixty-one patients were assessed at baseline, postintervention and at six-month follow-up. Resilience scores were significantly different between baseline and post-intervention assessments $(p<0.001)$, as well as at baseline and at six-month follow-up $(p<0.001)$. We observed a weak negative correlation between baseline resilience scores and HDRS scores at postintervention $(r=-0.295, p=0.015)$ and at six-month followup $(r=-0.354, p=0.005)$. Furthermore, we observed a weak negative correlation between resilience scores and HARS scores at post-intervention $(r=-0.292, p=0.016)$.

Conclusion: Subjects with higher resilience scores at baseline showed a lower severity of symptoms at post-intervention and at six-month follow-up.
\end{abstract}

Keywords: Cognitive therapy, resilience, major depression disorder, treatment response.

\section{Resumo}

Introdução: Poucos estudos têm avaliado medidas positivas de resposta terapêutica. Assim, o objetivo deste estudo foi verificar os efeitos da resiliência na severidade dos sintomas depressivos e ansiosos após psicoterapia cognitiva breve para depressão.

Métodos: Trata-se de um estudo de intervenção clínica aninhado a um ensaio clínico com dois diferentes modelos de terapia cognitiva. A Resilience Scale foi aplicada no baseline, enquanto que a Hamilton Anxiety Rating Scale e a Hamilton Depression Rating Scale foram utilizadas no baseline, após a intervenção e no acompanhamento de seis meses.

Resultados: Sessenta e um pacientes foram avaliados no baseline, no pós-intervenção e no acompanhamento de seis meses. Os escores de resiliência foram significativamente diferentes entre as avaliações de baseline e pós-intervenção $(p<0,001)$, bem como no baseline vs. acompanhamento de seis meses $(p<0,001)$. Observamos uma correlação negativa fraca entre os escores de resiliência no baseline e os escores de sintomas depressivos no pós-intervenção $(r=-0,295 ; p=0,015)$ e em seis meses de acompanhamento $(r=-0,354 ; p=0,005)$. Além disso, observamos uma correlação negativa fraca entre os escores de resiliência e sintomas ansiosos no pós-intervenção $(r=-0,292 ; p=0,016)$.

Conclusão: Indivíduos com maiores escores de resiliência na avaliação pré-tratamento apresentaram uma menor severidade de sintomas no pós-intervenção e no acompanhamento de seis meses.

Descritores: Terapia cognitiva, resiliência, transtorno depressivo maior, resposta terapêutica.

\footnotetext{
${ }_{1}^{1}$ Programa de Pós-Graduação em Saúde e Comportamento, Universidade Católica de Pelotas (UCPel), Pelotas, RS, Brazil. ${ }^{2}$ Mood Disorders Program, Department of Psychiatry \& Behavioural Neurosciences, McMaster University, Hamilton, ON, Canada. ${ }^{3}$ Programa de Pós-Graduação em Psiquiatria, Universidade Federal do Rio Grande do Sul (UFRGS), Porto Alegre, RS, Brazil.

Submitted Apr 12 2017, accepted for publication Jan 032018.

Suggested citation: Konradt CE, Cardoso TA, Mondin TC, Souza LDM, Kapczinski F, da Silva RA, et al. Impact of resilience on the improvement of depressive symptoms after cognitive therapies for depression in a sample of young adults. Trends Psychiatry Psychother. 2018;40(3):226-231. http://dx.doi. org/10.1590/2237-6089-2017-0047
} 


\section{Introduction}

Depression is the leading cause of disability worldwide and also a major contributor to the overall global burden of disease. ${ }^{1}$ The World Health Organization predicts that by 2020 depression will become the second leading cause of disease worldwide. ${ }^{2}$ Unless properly treated, depression can cause significant problems in a person's life. In addition, depression is associated with suicidal ideation. ${ }^{3} \mathrm{~A}$ review showed that resilience may prevent depressive symptoms, or at least reduce their impact. ${ }^{4}$ Thus, resilience is an important outcome to be assessed in subjects with depression.

Resilience is a complex multidimensional construct and few studies have assessed the factors involved in this phenomenon. It is known that stressful life events are associated with posttraumatic stress disorder, ${ }^{5}$ depression, and other psychiatric disorders. ${ }^{6}$ However, subjects can be exposed to stressful life events and not develop psychiatric disorders, a mechanism known as resilience. Thus, resilience is the ability to adapt successfully in the face of stress and adversity, maintaining normal psychological and physical functioning. ${ }^{7}$ One way to measure resilience is using scales. In Brazil, to the best of our knowledge, there is only one scale available to assess resilience, namely, the Resilience Scale. ${ }^{8}$ This scale is based on an instrument developed by Wagnild \& Young based on the report of women who successfully adapted to life adversities. ${ }^{9}$

Different intervention models can attenuate the impact of depressive symptoms on individual functions. Psychotherapeutic interventions are recommended in cases of mild or moderate depression. For the most severe forms of depression, the use of pharmacological or combined interventions is indicated. ${ }^{10}$ Variants of cognitive therapy have proven effective in reducing depressive symptoms ${ }^{11,12}$ and improving quality of life. ${ }^{13}$ Brief psychotherapy appears as an option in primary health care systems, with reduced costs when compared to traditional psychotherapies. ${ }^{14}$

Studies have mostly focused on predictors of poor treatment outcome and treatment dropout, whereas little attention has been given to positive measures. In this context, resilience is introduced as the ability of the individual to become adapted to a certain range of environmental contingencies. ${ }^{4}$ In other words, it is a dynamic process of positive adaptation in the context of significant adversity, an integration of adverse experiences and internal and external factors that may contribute to or prevent its occurrence at the individual level. ${ }^{8}$ Resilience can be understood as a protective factor for clinical outcomes, with important implications for health. ${ }^{8}$ In addition, it is suggested that clinical interventions may help promote resilience. ${ }^{4}$ Resilience is not a stable variable; therefore, it can be improved by psychological treatment, ${ }^{15}$ being an important outcome to be assessed.

Few studies have assessed the effect of positive measures, such as resilience capacity, on therapeutic response. Thus, the objective of this study was to assess the effects of resilience on severity of depressive and anxious symptoms after brief cognitive psychotherapy for depression. It is expected that individuals that are more resilient will show reduced depressive and anxious symptoms.

\section{Methods}

This was a follow-up clinical study nested in a doubleblind randomized clinical trial of two brief cognitive therapies (seven sessions): cognitive-behavioral therapy (CBT) ${ }^{16}$ and narrative cognitive therapy (NCT). ${ }^{17}$ The participants were drug-free young adults recruited from a convenience sample through advertisements in the community health center, centers of psychosocial assistance, and the local media. Inclusion criteria were: 1) being a young adult aged between 18-29 years; and 2) having a clinical diagnosis of major depressive disorder according to the Portuguese version of the Structured Clinical Interview for DSM-IV - Clinical Version (SCIDCV). ${ }^{18}$ Young adults were excluded from the study if the following criteria were met: 1 ) being in psychological or psychiatric treatment; 2) presenting a risk of suicide; 3) using a psychoactive substance (except for tobacco and alcohol); and 4) having a depressive episode due to bipolar disorder. The randomized clinical trial was approved by ethics committee of Universidade Católica de Pelotas (protocol no. 2009/24) and is published elsewhere. ${ }^{19}$ All subjects were informed about the experiment and agreed to participate by signing a free and informed consent.

Participants were interviewed using a sociodemographic questionnaire that investigated age, gender, family income, and educational level. Economic status was measured using the Brazilian National Economic Indicator (Indicador Econômico Nacional [IEN]). ${ }^{20}$ The Hamilton Depression Rating Scale (HDRS), an instrument consisting of 17 questions, was used to assess depressive symptoms. Its total score creates a discrete variable, where higher scores indicate greater severity. ${ }^{21}$ For the assessment of anxiety symptoms, we used the Hamilton Anxiety Rating Scale (HARS), which comprises 14 items. Again, higher total scores indicate higher severity of symptoms. ${ }^{22}$ The Resilience Scale was used to assess positive psychosocial adaptation levels 
in the face of important life events. This instrument is composed of 25 items; each item assesses the level of positive psychosocial adaptation to important life events and ranges from 1 (totally disagree with the sentence) to 7 (totally agree with the sentence). The global score ranges from 25 to 175 points, with higher scores indicating higher resilience. ${ }^{8}$ The scale was adapted and validated to Brazil by Pesce et al. ${ }^{8}$ The cross-cultural adaptation showed good results in the semantic equivalence for general meaning (above 90\%) and referential meaning (above 85\%). Chronbach alpha was 0.80 . Kappa was regular and moderate, and the intra-class correlation coefficient was $0.746(p<0.001)$. Construct validity demonstrated direct and significant correlation with self-esteem, family supervision, life satisfaction, and social support. ${ }^{8}$

Both groups (CBT and NCT) were included in the resilience analysis. Since there were no differences between the two intervention models regarding resilience scores at baseline $(p=0.124)$, at post-intervention (immediately after the 7th session) $(p=0.142)$, or at six-month follow-up $(p=0.920)$, the two groups were considered together in the analysis, regardless of the type of therapy. Assessments were performed at baseline, postintervention, and at six-month follow-up. Researchers responsible for follow-up assessments were blinded to the intervention model. All assessments were coded and data were entered into an Epi-Info 6.04d database and validated by means of double data entry. Statistical analysis was conducted using the Statistical Package for the Social Sciences (SPSS) version 21.0. Chi-square, $t$-test, and Pearson correlation were used to assess potential confounders $(p<0.2)$. Linear regression was used to assess the association between baseline resilience scores and severity of depressive and anxious symptoms at post-intervention and six-month follow-up, adjusting for depressive and anxious symptoms at baseline.

\section{Results}

Ninety-one drug-free adults (18-29 years) were included in this study. Regarding sample characteristics,
$75.8 \% \quad(n=69)$ were women, the mean age was $23.98 \pm 3.38$ years, and the mean number of years of education was $12.64 \pm 3.12$. The rate of treatment dropout was $25.3 \%(n=23)$. There were no differences between individuals who completed the treatment and those who dropped out regarding gender $(p=0.169)$, age $(p=0.915)$, years of education $(p=0.598)$, or socioeconomic status $(p=0.709)$. In addition, there were no significant differences in mean baseline resilience scores between those who completed the treatment $(108.07 \pm 21.14)$ and those who did not $(105.00 \pm 24.28)$ $(p=0.563)$.

Sixty-eight patients completed the study and were assessed post-intervention, and 61 patients were assessed at six-month follow-up. Table 1 shows the clinical characteristics of the sample at baseline and at follow-up assessments. Brief cognitive therapies improved depressive and anxious symptoms at postintervention and at six-month follow-up.

Resilience scores were significantly different between baseline and post-intervention assessments $(p<0.001)$, as well as between baseline and at sixmonth follow-up $(p<0.001)$. However, there were no significant differences in resilience scores obtained postintervention and at six-month follow-up ( $p=0.115)$.

Figure 1 shows a weak negative correlation between resilience scores at baseline and HDRS scores at postintervention $(r=-0.295, p=0.015)$, and also between resilience scores at baseline and HDRS scores at sixmonth follow-up $(r=-0.354, p=0.005)$. Furthermore, Figure 2 shows a weak negative correlation between resilience scores at baseline and HARS scores at postintervention $(r=-0.292, p=0.016)$. This association remained statistically significant after adjusting for depressive and anxious symptoms at baseline.

\section{Discussion}

This study aimed to assess the impact of resilience on severity of depressive and anxious symptoms after brief cognitive psychotherapies for depression. The results showed that patients with higher baseline

Table 1 - Clinical characteristics of the study sample at baseline (t1), post-intervention (t2), and six-month follow-up (t3)

\begin{tabular}{|c|c|c|c|c|c|}
\hline Variables & $\begin{array}{c}\text { Baseline (t1) } \\
n=91\end{array}$ & $\begin{array}{c}\text { Post-intervention (t2) } \\
n=68\end{array}$ & $\begin{array}{l}\text { p-value } \\
\text { t1 vs. t2 }\end{array}$ & $\begin{array}{l}\text { Six-month follow-up (t3) } \\
\qquad n=61\end{array}$ & $\begin{array}{l}\text { p-value } \\
\text { t1 vs. t3 }\end{array}$ \\
\hline Mean resilience scores & $105.5 \pm 22.47$ & $125.2 \pm 24.2$ & $\mathrm{p}<0.001$ & $128 \pm 28.53$ & $\mathrm{p}<0.001$ \\
\hline Mean HDRS scores & $11.80 \pm 3.53$ & $5.69 \pm 4.44$ & $\mathrm{p}<0.001$ & $5.56 \pm 4.45$ & $\mathrm{p}<0.001$ \\
\hline Mean HARS scores & $15.68 \pm 5.87$ & $7.25 \pm 5.78$ & $\mathrm{p}<0.001$ & $8.33 \pm 6.99$ & $\mathrm{p}<0.001$ \\
\hline
\end{tabular}

HARS = Hamilton Anxiety Rating Scale; HDRS = Hamilton Depression Rating Scale. 
resilience scores showed less severe symptoms at postintervention and at six-month follow-up. In addition, the patients improved resilience scores at postintervention, and the improvement was maintained at six-month follow-up.

In this study, patients with higher baseline resilience scores showed less severe depressive and anxious symptoms at post-intervention. We found no studies that evaluated the effects of resilience on the improvement of depressive and anxious symptoms after psychotherapeutic interventions. However, a recent study found that higher levels of resilience are associated with higher levels of quality of life in subjects with bipolar disorder, schizophrenia, and heathy controls. ${ }^{23}$ In addition, another study with patients with chronic obstructive pulmonary disease showed that resilience contributed significantly to reduce the levels of anxiety, depression, and stress. Likewise, it has also been shown to reduce disease-specific pulmonary impairment after drug intervention. ${ }^{24}$ In this respect, the researchers emphasize that resilience may have an important role in the treatment of these disorders. ${ }^{25,26}$

We found that patients with higher baseline resilience scores showed less severe symptoms also at six-month follow-up. Some authors suggest that resilience is a protective factor that may help prevent relapse, since it is generally thought of as an adaptation in the face of adversity, trauma, tragedy, threats, or stress. ${ }^{15,27}$ In this sense, studies about resilience in a therapeutic context are important to reinforce the interaction of resilience with improvement of psychological well-being.

The results obtained for resilience were different at baseline vs. at post-intervention, i.e., less resilient patients showed higher resilience scores after treatment, demonstrating the possible effect of psychotherapy on resilience. Similarly, a study with

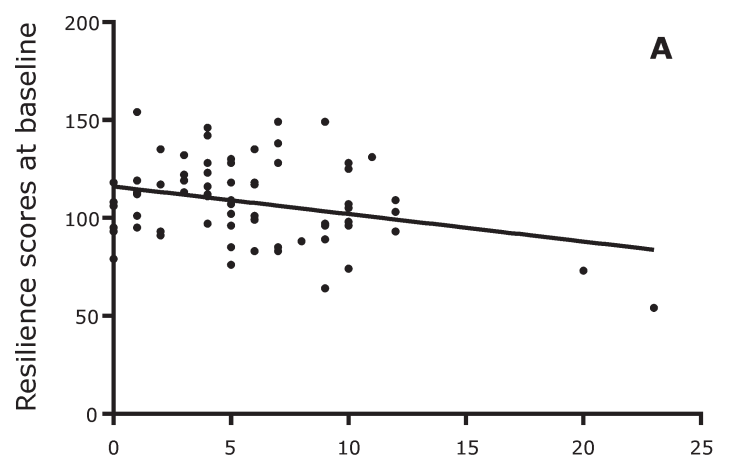

Depressive symptom scores at post-intervention

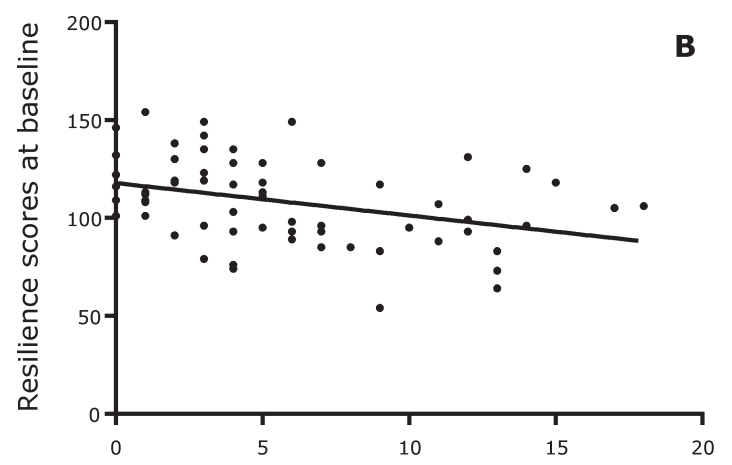

Depression symptom scores at six-month follow-up

Figure 1 - Correlation between resilience scores at baseline and depressive symptom scores at post-intervention and at six-month follow-up. A) Post-intervention: $r=-0.295, p=0.015$; B) Six-month follow-up: $r=-0.354, p=0.005$.

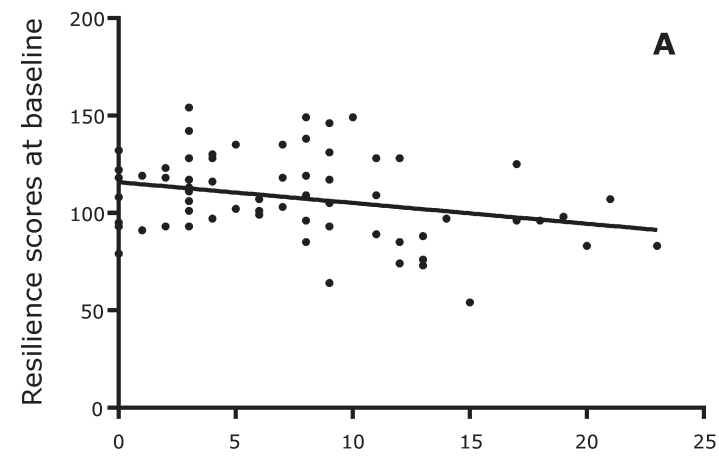

Anxious symptom scores at post-intervention

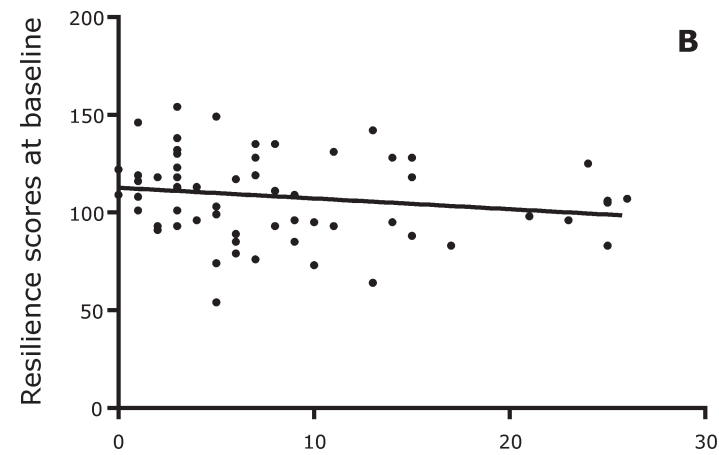

Anxious symptom scores at six-month follow-up

Figure 2 - Correlation between resilience scores at baseline and anxious symptom scores at post-intervention and at six-month follow-up. A) Post-intervention: $r=-0.292, p=0.016$; B) Six-month follow-up: $r=-0.172, p=0.184$. 
depressed and anxious adolescents showed higher resilience scores as well as improvement of symptoms at post-treatment. ${ }^{15}$ Another study examined the use of CBT to enhance resilience among adolescents whose parents were alcohol-dependent. The participants were submitted to 10 brief psychotherapy sessions. Resilience scores increased significantly after the intervention. ${ }^{28}$ These data together reinforce the positive effect of psychotherapy on resilience and confirm that resilience is a dynamic process that can be changed in psychotherapy. Nevertheless, our data should be interpreted considering some limitations. We did not have a control group nor did we assess the resilience of the subjects who dropped out from treatment, which did not allow us to affirm that resilience improved due to psychotherapy. However, our data showed a significant increase in resilience scores from baseline to followup assessments (after psychotherapy). Resilience could possibly be improved because of psychological treatment; however, more studies with a control group are needed to confirm this finding.

According to the literature, less than $50 \%$ of patients with major depressive disorder complete six months of follow-up ${ }^{13}$ after the end of treatment. Authors report that patients with high resilience tend to follow treatment correctly and seek for health care. ${ }^{29}$ However, in this study, no differences were found between the resilience scores of individuals who completed the treatment and of those who dropped out before completion. In this particular case, resilience was not a predictor of treatment adherence. To the best of our knowledge, there are no studies assessing resilience as a contributing factor to the permanence of the individual in treatment or dropout rates associated with therapeutic resilience.

A limitation of the present study was its small sample, which may have influenced the interpretation of the results. Our results showed a weak correlation, possibly due to the small sample size. Thus, more studies are needed to confirm our findings. Another limitation was that the findings could not be extrapolated to patients with severe depression or suicide risk, since these characteristics were considered exclusion criteria for this study. In addition, resilience is a new concept in the research field, which may limit the interpretation of the findings. In contrast, this study presents some important contributions. The sample was composed of young people with few previous interventions, probably with early episodes of depression. Similarly, the evaluation of depressive symptoms and resilience at the end of treatment and at six-month follow-up may have contributed to differentiate our study from others using these variables. It is noteworthy that most of the studies tend to focus on risk factors for poor therapeutic response and the few studies that evaluate the effect of resilience generally investigate very specific samples.

The role of resilience-related factors in psychotherapy is still little explored. ${ }^{30}$ There is lack of research to assess resilience as a positive predictor of therapeutic response after brief cognitive interventions. Brief interventions and less costly therapies facilitate research in this field, benefiting patients in remission of depressive and anxiety symptoms, and therefore improving their quality of life. However, further studies are needed to advance research on this topic.

\section{Acknowledgements}

This study received a grant from the Políticas Públicas para o SUS (PPSUS) program, of Conselho Nacional de Desenvolvimento Científico e Tecnológico (CNPq).

\section{Disclosure}

No conflicts of interest declared concerning the publication of this article.

\section{References}

1. Organização Mundial de Saúde. Tradução do Centro Colaborador da OMS para a Classificação de Doenças em português. 6a ed. São Paulo: EDUSP; 1998.

2. Zavaschi $M L$, Satler $F$, Poester $D$, Vargas $C F$, Piazenski R, Rohde LAP, et al. Associação entre trauma por perda na infância e depressão na vida adulta. Rev Bras Psiquiatr. 2002;24:189-95.

3. Lafer B, Almeida OP, Fráguas R Jr., Miguel EC, editores. Depressão no ciclo de vida. Porto Alegre: Artmed; 2000.

4. Edward KL. Resilience: a protector from depression. J Am Psychiatr Nurses Assoc. 2005;11:241-3.

5. Visser E, Gosens T, Den Oudsten BL, De Vries J. The course, prediction and treatment of acute and post-traumatic stress in trauma patients: a systematic review. J Trauma Acute Care Surg. 2017:82:1158-83.

6. Jansen K, Cardoso TA, Mondin TC, Matos MB, Souza LD, Pinheiro RT, et al. Stressful life events and mood disorders: a community sample. Cien Saude Colet. 2014;19:3941-6.

7. Wu G, Feder A, Cohen H, Kim JJ, Calderon S, Charney DS, et al. Understanding resilience. Front Behav Neurosci. 2013;7:10.

8. Pesce RP, Assis SG, Avanci JQ, Santos NC, Malaquias JV, Cavalhaes R. Adaptação transcultural, confiabilidade e validade da escala de resiliência. Cad Saude Publica. 2005;21:436-48.

9. Wagnild GM, Young HM. Development and psychometric evaluation of resilience scale. J Nurs Meas. 1993;1:165-78.

10. Fournier JC, DeRubeis RJ, Hollon SD, Dimidjian S, Amsterdam JD, Shelton RC, et al. Antidepressant drug effects and depression severity: a patient-level meta-analysis. JAMA. 2010;303:47-53.

11. Leichsenring F. Comparative effects of short-term psychodynamic psychotherapy and cognitive-behavioral therapy in depression: a meta-analytic approach. Clin Psychol Rev. 2001;21:401-19.

12. Segal $Z$, Vincent $P$, Levitt $A$. Efficacy of combined, sequential and crossover psychotherapy and pharmacotherapy in improving outcomes in depression. J Psychiatry Neurosci. 2002;27:281-90.

13. Papakostas GI, Petersen T, Mahal Y, Mischoulon D, Nierenberg AA, Fava M. Quality of life assessments in major depressive disorder: a review of the literature. Gen Hosp Psychiatry. 2004;26:13-7. 
14. Scott C, Tacchi MJ, Jones R, Scott J. Acute and one-year outcome of a randomised controlled trial of brief cognitive therapy for major depressive disorder in primary care. $\mathrm{Br}$ J Psychiatry. 1997; 171:131-4.

15. Pakalniškienè $V$, Viliūnienè $R$, Hilbig $J$. Patients' resilience and distress over time: is resilience a prognostic indicator of treatment? Compr Psychiatry. 2016;69:88-99.

16. Beck AT, Rush AJ, Shaw BF, Emery G. Terapia cognitiva da depressão. Porto Alegre: Artes Médicas; 1997.

17. Gonçalves OF. Psicoterapia cognitiva narrativa: manual de terapia breve. Minho: Psy; 1998.

18. Del-Ben CM, Vilela JA, Crippa JAS, Hallak JE, Labate CM, Zuardi AW. Reliability of the Structured Clinical Interview for DSM-IV Clinical Version translated into Portuguese. Rev Bras Psiquiatr. 2001;23:156-9.

19. Cardoso TA, Mondin TC, Spessato BC, Quevedo LA, Souza LDM, Silva RA, et al. The impact of anxious symptoms in the remission of depressive symptoms in a clinical trial for depression: followup of six months. J Affect Disord. 2014;168:331-6.

20. Barros AJ, Victora CG. A nationwide wealth score based on the 2000 Brazilian demographic census. Rev Saude Publica. 2005;39:523-9.

21. Hamilton M. Development of a rating scale for primary depressive illness. Br J Soc Clin Psychol. 1967;6:278-96.

22. Hamilton $\mathrm{M}$. The assessment of anxiety states by rating. $\mathrm{Br}$ J Med Psychol. 1959;32:50-5.

23. Hofer $A$, Mizuno $Y$, Wartelsteiner $F$, Wolfgang Fleischhacker $W$, Frajo-Apor B, Kemmler G, et al. Quality of life in schizophrenia and bipolar disorder: The impact of symptomatic remission and resilience. Eur Psychiatry. 2017:46:42-7.

24. Keil DC, Vaske I, Kenn K, Rief W, Stenzel NM. With the strength to carry on: the role of sense of coherence and resilience for anxiety, depression and disability in chronic obstructive pulmonary disease. Chron Respir Dis. 2017;14:11-21.

25. Min JA, Jung YE, Kim DJ, Yim HW, Kim JJ, Kim TS, et al. Characteristics associated with low resilience in patients with depression and/or anxiety disorders. Qual Life Res. 2013;22:23141.

26. Southwick SM, Charney DS. The science of resilience: implications for the prevention and treatment of depression. Science. 2012;338:79-82.

27. Brietzke $E$, Kauer-Sant'anna M, Jackowski A, Grassi-Oliveira $R$, Bucker J, Zugman A, et al. Impact of childhood stress on psychopathology. Rev Bras Psiquiatr. 2012;34:480-8.

28. Hyun MS, Nam KA, Kim MA. Randomized controlled trial of a cognitive-behavioral therapy for at-risk Korean male adolescents. Arch Psychiatr Nurs. 2010;24:202-11.

29. Smith PR. Resilience: resistance factor for depressive symptom. J Psychiatr Ment Health Nurs. 2009;16:829-37.

30. Norte CE, Souza GGL, Pedroso AL, Mendonça-de-Souza ACF, Figueira I, Volchan $\mathrm{E}$, et al. Impact of cognitive-behavior therapy on resilience-related neurobiological factors-Norte. Rev Psiq Clin. 2011;38:43-5.

\section{Correspondence:}

\section{Karen Jansen}

Rua Gonçalves Chaves, 373, sala 424C

96015-560 - Pelotas, RS - Brazil

E-mail: karen.jansen@pq.cnpq.br / karen.jansen@ucpel.edu.br Tel. : +55 (53) 21188404 